\title{
The Impact of Free Lunch on Attendance at Voluntary Teacher Training
}

\section{Dr. Todd Easton, Kansas State University}

Todd Easton received a B.S. in Mathematics with a minor in Statistics from Brigham Young University (1993), an M.S. in Operations Research from Stanford University (1994) and a Ph.D. in Industrial Engineering from Georgia Institute of Technology (1999). He worked as a post-doctoral fellow at Georgia Institute of Technology until 2001, when he joined the Industrial and Manufacturing Systems Engineering department at Kansas State University. He is a University Distinguished Teaching Scholar and an Assistant Professor. His research interests are in combinatorial optimization and teaching techniques. 


\title{
The Impact of Free Lunch on Attendance at Voluntary Teacher Training
}

\author{
Todd Easton \\ Industrial and Manufacturing Systems Engineering \\ Kansas State University \\ teaston@ksu.edu
}

\begin{abstract}
Even though most faculty spend over one quarter of their time engaged in teaching activities, universities do not require continued teacher training. Thus, most attendees at teacher training events have voluntarily come to the event and sacrificed time away from other duties or opportunities. Successful teacher training programs must first have attendees. This paper presents a case study showing that free lunch increases faculty attendance by about $36 \%$ at teacher training workshops. Even though offering free lunch increases attendance by a statistically significant amount, the number of samples is small and causality should not necessarily be inferred. Since faculty sacrifice time to attend, the paper also discusses the importance of the quality and speed of such workshops. Some suggestions for ideas and structure are provided. Given the cost of lunch and the potential long-term benefits of improving a faculty member's teaching, future teacher training sessions should offer free lunch or other benefits to increase attendance.
\end{abstract}

Key Words: Teacher Training, Voluntary Attendance, Workshop Structure

\section{Introduction}

The responsibilities of a college or university faculty member are incredibly diverse. Most faculty have responsibilities to teach, perform research, develop courses and curriculum, review papers, recruit students and serve on various committees. The amount of skills that a faculty needs to be successful in many of these endeavors is immense.

Over the course of a career, most faculty spend an enormous amount of time teaching. Even faculty at universities focusing on research with a 2/1 load (two classes one semester and one class the other semester) spend well over 1,000 hours in charge of a classroom (Kansas State University Handbook 2018) over a 10 year span. This time does not include office hours, preparation, grading or any of the other related teaching activities.

Surprisingly, Kansas State University requires no teacher training. Furthermore, the amount of training offered upon starting a faculty job is short and primarily focused on the legal aspects and requirements of teaching. This lack of teacher training is also found in various institutions (Dimeo, 2017). Such universities obviously believe that achieving a Ph.D. qualifies an individual to teach. Furthermore, these institutions do not prioritize that faculty members improve their 
teaching abilities. Consequently, teacher training or improvement is entirely optional for its faculty.

Many universities have a center that focuses on quality teaching and training. This group offers training and other opportunities to help enhance a faculty members teaching. Occasionally, a faculty member is floundering in the classroom, and administration may require attendance to a few of these teacher training activities. However, the bulk individuals attending any type of teacher training is voluntary.

The Coalition on the Academic Workforce (2012) reported that professional development for teaching is minimal and is even worse for nontenure track faculty and tenured faculty. These individuals are frequently left to their own resources or desires to improve their teaching. Robinson and Hope (2013) comment on how little has changed and that this lack of teacher training has existed for some time.

In contrast, the majority of states require every high school, middle school or elementary teacher to be licensed. This license is typically valid for five years. A critical piece of the recertification is continued training. The majority of states require between 50 and 200 hours of continued training over this five year period (Continuing Education, 2018). Thus, these teachers spend, on average, over 10 hours a year in professional development activities designed to improve teaching.

Much research has been done on the quality of teaching and its impact on student learning (Condon et al. 2016, Vescio et al. 2008). As expected, improving a teacher's quality of instruction directly impacts student learning. Furthermore, improved teaching should also improve retention and graduation rates.

Someday universities may require continued teacher training. Until then, faculty are left to decide whether or not to attend teacher training. This paper focuses on how to entice faculty to pursue teacher training. The primary finding and contribution of this work is that lunch is sufficient to significantly increase enrollments for a teaching training workshop. The data is self reported and the sample size is small, so additional studies should be done before claiming a strong causality link between lunch and attendance at teaching workshops.

This paper's secondary contribution briefly describes the importance of a teaching workshop's structure. Since faculty sacrifice their valuable time to attend, the workshop should have numerous topics that are briefly covered. Faculty are intelligent and typically modify any teaching technique to their own personality. Thus, several brief introductions to numerous topics should enable the faculty to attempt a few new classroom techniques.

The remainder of the paper is organized as follows. The next section describes the study and analyses the data regarding the impact of lunch on attendance. Section 3 focuses on creating useful teacher training workshops. The paper concludes in Section 4 with some comments for future research. 


\section{Attendance at Teaching Workshops or Training Sessions}

In May 2017, the author was awarded the permanent title of University Distinguished Teaching Scholar at Kansas State University. This award is only given to one faculty member a year and carries the responsibility of improving faculty teaching for a year. The author chose to develop a workshop on improving student engagement in the classroom. The workshop covers techniques to passively engage students and several active learning techniques.

Understanding that faculty time is valuable and that the author had not been to any teacher training over the past 15 years, the author chose to create an extremely short workshop that only lasted one hour. The plan was to offer four workshops during the first semester and several the following semester. The first workshop was scheduled for a Tuesday between 11:30 and 12:30. After feedback from the first workshop, it was decided to change the workshop to 90 minutes and the next two workshops were each two weeks apart and offered on Tuesdays from 11:0012:30. The semester's final workshop was offered the Friday before finals. These workshops continued the following semester.

To advertise the workshops, the university's teaching and learning website posted all of these workshops at least a month in advance. Faculty were asked to register via email. Due to the author's new title and a general interest from the teaching community, five individuals registered for the first Tuesday workshop and two individuals registered for the one Friday workshop. The author noted that these individuals are consistently involved in the university's teaching and learning center.

One week before the first workshop, the author submitted an event announcement to the university's announcement page. It read "Workshop: Teaching Tools to Improve Student Learning and Teacher Evaluations. Learn new teaching techniques and strategies." Each day faculty receive the list of announcements and it is believed that many faculty may not read this posting. In the 24 hour period after this announcement three additional people registered. One individual registered about 72 hours after this announcement. It is believed that these four individuals enrolled due to this announcement.

Individuals were emailed a reminder the day before the workshop and told that lunch would be offered. For the first workshop one individual failed to come and one person came without registering. Thus, nine individuals came to the first workshop. Each individual filled out an evaluation form at the end and had an opportunity to provide feedback to improve the workshop.

The most useful feedback was the lack of time and all future workshops were changed to 90 minutes. Observe that the first three seminars have overlapping times and thus fewer faculty should be able to attend the 90 minute version when compared to the number that could attend the 60 minute version. Furthermore, one would also expect enrollments to diminish because the people associated with the teaching and learning center would not be coming a second time to the same workshop. Finally, fewer faculty should be willing to sacrifice 90 minutes for a teaching workshop. Consequently, one expects to see the attendance below nine at any future workshop. 
One week before the second Tuesday workshop, the author posted an announcement to the university's page. "Workshop: Teaching Tools to Improve Student Learning and Teacher Evaluations. Come enjoy a free lunch and learn new teaching techniques and strategies." The author now offered lunch to help encourage faculty to attend. The idea is to test whether or not lunch is sufficient motivation to have faculty attend a teaching workshop.

There were no preregistered people for this Tuesday. The workshop room only holds 20 . The author received 25 preregistrations within 24 hours. Furthermore, a total of 30 individuals tried to preregister during the week. Any individual registering after 20 were told about the other two workshops and asked if they would register for either of those. Of the ten individuals that exceeded the capacity, four registered for the last Tuesday and four registered for the Friday workshop and two did not register. A reminder email was sent the day before and 19 of the 20 registered people attended and one person brought an unregistered faculty member.

One week before the third Tuesday's workshop, the author posted the same announcement offering lunch. The author received 14 registrations within the week. A reminder email was sent and four of the 18 preregistered participants did not attend.

One week before the Friday workshop, the author posted the same announcement offering lunch. The author received 18 preregistrations within the week. Two individuals were not allowed to participate. A reminder email was sent a day before and there were 18 participants at the workshop.

The author offered this workshop the following semester and followed a similar process. Lunch was advertised for all workshops. A total of 147 individuals attended the workshop. Eleven people had to leave a few minutes early and did not fill out a survey. Of the attendees, four said that they were required or strongly encouraged to come. The rest came voluntarily. The relevant numbers for all of these workshops are contained in Table 1.

Even though all participants received a free lunch, only the last eight groups knew this prior to signing up. A survey question asked how much of an impact lunch had on their decision to participate in the workshop (none, some, would not have come without lunch). A total of 127 surveys were filled out by individuals that knew about the lunch. Of the people, $45(35.7 \%)$ said that lunch had some impact or that they would not have come without lunch. Furthermore, of the 82 individuals that said lunch had no impact on attendance, eleven surveys had notes that said it was either a bonus or that it helped. Thus, the self-reported questionnaires reflect over a third increase in attendance due to lunch.

Even with this limited number of data points, one can statistically test whether or not the mean of the lunch workshops is equal to 9, the number of people attending the workshop that did not have an advertised lunch. A two sided $t$ test with unknown variance was performed to see if the mean of the number of attendees at the workshop with lunch advertised was equal to 9 . The significance is set at $99 \%$. The $p$ value for this test is .00015 , and the $99 \%$ confidence interval ranges from 13.83 to 20.67 . Thus, one rejects the null hypothesis with $99 \%$ confidence. Consequently, one can conclude that the number of participants is statistically higher if lunch is offered. However, the sample size is small and additional workshops without lunch being advertised should be obtained prior to claiming a strong causation between lunch and attendance. 
Table 1: Summary of the attendance for the four workshops

\begin{tabular}{|l|c|c|c|}
\hline Workshop & Number preregistered & Number attending & Lunch impacted attendance \\
\hline 1. No lunch advertised & 9 & 9 & N/A \\
\hline 2. Lunch advertised & 30 & 20 & 5 \\
\hline 3. Lunch advertised & 18 & 14 & 7 \\
\hline 4. Lunch advertised & 21 & 19 & 7 \\
\hline 5. Lunch advertised & 19 & 19 & 5 \\
\hline 6. Lunch advertised & 20 & 19 & 5 \\
\hline 7. Lunch advertised & 20 & 15 & 6 \\
\hline 8. Lunch advertised & 17 & 13 & 4 \\
\hline 9. Lunch advertised & 20 & 19 & \\
\hline
\end{tabular}

The importance of these additional attendees, due to lunch, is far more impactful then one may think. During this second semester, these workshops were offered as long as demand was sufficient. Without these additional attendees, the first three workshops would have had 14, 12 and 10 participants. The demand would have clearly diminished and the last two workshops would not have occurred. The additional attendance enables the presenter and sponsor of the workshops to believe that the impact is substantial enough to continue.

Although more faculty attended the seminars with lunch, the overall attendance was not overly impressive. During all of the workshops, roughly $7 \%$ of the university's faculty came to this training, which is far less than would come if continued training were required. In fact, the author's primary goal was to help the Mathematics faculty become better teachers. To this end, conversations occurred with the department chair and an effort was made to present in a faculty meeting. Lunch or dinner was offered, which was politely declined. In a final desperate move, $\$ 1,000$ in office supplies was offered to the Mathematics Department if the author could present at a faculty meeting. Sadly, this offer was also rejected. Even though more people attended the workshop due to lunch, some faculty have no desire to participate in teacher training. In fact, some people would pass up a reasonable amount of money to avoid teacher training.

\section{Teaching Training Suggestions}

When preparing professional development to improve teaching for university faculty, one should recognize that the majority of attendees will come voluntarily or not at all. Due to this fact, the training must be impactful. Second university faculty are intelligent, have advanced degrees and are capable of critical thought. Thus, training does not need to spell out every single detail and should leave some of the finer points to the curiosity or development of the attendees. Third, faculty have numerous jobs and responsibilities and the training should be fairly short and conveniently scheduled.

With these guiding principles, the author developed a 90 minute teacher training workshop with no registration fee that met on campus. The workshops always occurred near lunch time and provided free lunch. The amount of "usable" time spent by the faculty to attend can be estimated to be only 45 minutes, (assuming an hour lunch break and 15 minutes of walking/travel time). Thus, the workshops were not prohibitively inconvenient to faculty. 
The workshop focused on covering various techniques on engagement. In about 75 minutes a broad overview of passive engagement and active engagement/active learning techniques (Prince, 2004) were presented. The presented active learning techniques were student voting (Martyn, 2007), pair and share (Kolthiyal et al. 2013), problem based learning (Stearns et al. 2012), muddiest point (Kwan 2011) and lecture based tutoring (Easton, 2015, Easton, 2016). The attending faculty took the role of the students and the author was the teacher.

In this setting, participants became students in each of these learning techniques. For instance, a brief outline of student voting is presented. This is followed by the question "Up until now, the workshop has only used passive engagement. How engaged were you? None, some, or entirely engaged." The attendees raised their hands to vote and the author summarized the results and led a discussion as to why. Thus, every participant played the role of a student and experienced student voting in a classroom setting. Similar strategies are used for the other methods. That is, participants were asked whether or not student voting with hands or technology was better. Participants responded to this question through the pair and share technique.

To study and analyze the effectiveness of the workshop, all 136 participant surveys are considered and not just the individuals knowing that free lunch would be provided. With six topics covered in 75 minutes, the pace of the workshop was brisk. Each topic has about 5-20 minutes, depending upon the complexity of the technique. The final 5-15 minutes is left for the attendees to plan how to implement one of these techniques in a class.

One survey question asks about the speed of the workshop. Not one person said that the pace was slow or too slow. In fact, 11 stated that it was too fast, 43 fast and 82 said just right. The author observed that the faculty were intelligent and an extremely short presentation on each topic was sufficient to understand the technique. Furthermore, any faculty implementing a technique will adjust and personalize the tool.

Another survey question asked how useful the workshop was. Eighty five stated the workshop was very useful, 41 above average and 10 average. No participants stated it was below average or poor. As one would expect, the workshops generally improved over time and the last five workshops only had a total of four people rating the workshop as average.

Two questions asked regarding what techniques the faculty learned a reasonable amount and how many methods that they plan on trying. Figure 1 provides the questions and the responses. All participants stated that they would try at least one teaching tool and the average was 2.6. Thus, there is evidence to show that this workshop is effective and valuable. The follow up on whether or not the attendees tried and still use a teaching technique is left for future research.

The goal of teacher training workshops should be to have the participants improve their teaching. To this end, the author recommends that one should present numerous tools so that the participants can identify new methods that fit the participants' personality. The pace of material should move at a brisk pace to decrease the amount of time that the attendees' sacrifice. To help encourage attendance, lunch should be provided, registration should be free and the event should be conveniently located. 
Figure 1: Questions relating to the workshop's teaching techniques

How many teaching techniques did you gain a reasonable amount of knowledge?

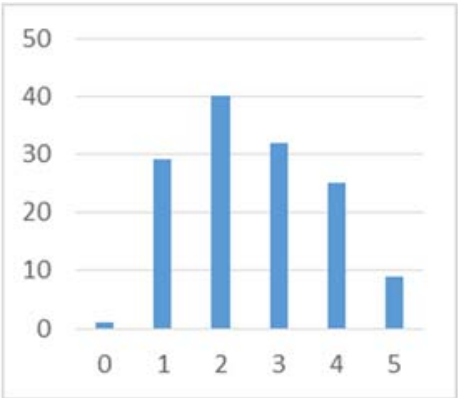

Average 2.57
How many of these techniques will you attempt to implement in the next year?

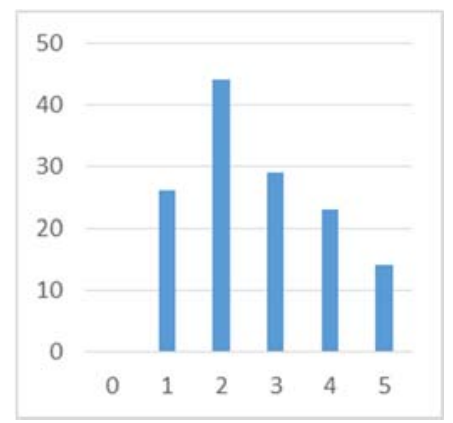

Average 2.67

\section{Conclusions and Future Research}

Faculty spend enormous amounts of time teaching with minimal training. Until universities mandate continued teacher training, most attendees at such training events are sacrificing their valuable time. This paper shows that offering free lunch will increase attendance by about one third at teacher training workshops, which is a statistically significant amount. However, the sample size is small and causality cannot be strongly inferred. Additionally, the paper describes ideas and concepts to help such training events be well received. Thus, future teacher training sessions are encouraged to request funds for lunch and to develop a short, fast paced session that is offered in a convenient location around lunchtime.

There remain several future research topics worth pursuing. One of the most important is whether or not universities should mandate teacher training on some regular basis and the impact of such a mandate. Another research topic involves the types of teaching tools that are most effective and easily implemented in a classroom. Such a result would enable future teacher training to focus on the tools that are most likely to succeed. Finally, one could attempt to identify the amount and type of benefits required to have most individuals participate in voluntary training sessions.

\section{References}

ACUE (2018) Why colleges and universities need to invest in quality teaching more than ever. Available at http://acue.org/quality-teaching/ [Accessed January 30, 2018]

Condon, W., Iverson, E. R., Manduca, C. A., Rutz, C., \& Willett, G. (2016). Faculty development and student learning: Assessing the connections. Indiana University Press.

Dimeo, J. (October 11, 2017) "How colleges train instructors to teach online courses - Inside Higher Ed" Inside higher Ed. Available at https://www.insidehighered.com/digital- 
learning/article/2017/10/11/how-colleges-train-instructors-teach-online-courses [Accessed January 20, 2017].

T. Easton. (2015) "Improving student ratings through lecture based tutoring." Proceedings of ASEE Zone III Conference Gulf Southwest - Midwest - North Midwest Sections) September 2015, Springfield, MO, USA, 2015, 1-8.

Easton, T. (2016) "Implementing lecture based tutoring to improve student learning." Proceedings of ASEE Zone III Conference Gulf Southwest - Midwest - North Midwest Sections) September 2016, Manhattan, KS 1-9.

Kansas State University Handbook (2018) Section, F115. Available at http://www.kstate.edu/provost/universityhb/fhsecf.html [Accessed March 14, 2018].

Kothiyal, A., Majumdar, R., Murthy, S., \& Iyer, S. (2013, August). Effect of think-pair-share in a large CS1 class: $83 \%$ sustained engagement. In Proceedings of the ninth annual international ACM conference on International computing education research (pp. 137-144). ACM.

Kwan, F. (2011). Formative assessment: the one-minute paper vs. the daily quiz. Journal of Instructional Pedagogies, 5, 1.

Martyn, M. (2007). Clickers in the classroom: An active learning approach. Educause quarterly, 30(2), 71 .

Prince, M. (2004). Does active learning work? A review of the research. Journal of engineering education, 93(3), 223-231.

Robinson, T. E., \& Hope, W. C. (2013). Teaching in higher education: is there a need for training in pedagogy in graduate degree programs? Research in Higher Education Journal, 21.

Tapilouw, M. C., Firman, H., Redjeki, S., \& Chandra, D. T. (2017). The importance of training needs' questionnaire in order to arrange science teacher training program. Jurnal Pendidikan IPA Indonesia, 6(1).

Teach Tomorrow (2018) A complete guide to continuing education for teachers. American. Available at https://www.teachtomorrow.org/continuing-education-for-teachers/ [accessed Jan $10,2018]$.

Vescio, V., Ross, D., \& Adams, A. (2008). A review of research on the impact of professional learning communities on teaching practice and student learning. Teaching and teacher education, 24(1), 80-91. 